\title{
PAULETTE .DIETERLEN*
}

\section{Liberalismo y democracia}

Torberto Bobbio en el libro llamado El futuro de la democracia ${ }^{1}$ I se refiere a las relaciones entre el liberalismo y la democracia de la siguiente manera:

El Estado liberal no solamente es el supuesto histórico, sino también jurídico del Estado democrático. El Estado liberal y el Estado democrático son interdependientes en dos formas: 1) en la línea que va del liberalismo a la democracia, en el sentido de que son necesarias ciertas libertades para el correcto ejercicio del poder democrático; 2) en la línea opuesta, la que va de la democracia al liberalismo, en el sentido de que es indispensable el poder democrático para garantizar la existencia y la persistencia de las libertades fundamentales. En otras palabras, es improbable que un Estado no liberal pueda asegurar un correcto funcionamiento de la democracia y por otra parte es poco probable que un Estado no democrático sea capaz de garantizar las libertades fundamentales. La prueba histórica de esa interdependencia está en el hecho de que el Estado liberal y el Estado democrático cuando caen, caen juntos. ${ }^{2}$

Aun cuando me parece que la afirmación de Bobbio es correcta, creo que la relación entre liberalismo y democracia debe ser examinada con cierto rigor. Para hacer este examen es necesario dar una definición de estos términos.

\footnotetext{
Instituto de Investigaciones Filośficas, UNAM.

${ }^{1}$ México, F.C.E., 1986.

${ }^{2}$ Ibid, p. 15.
} 
Por democracia entenderé, como Bobbio,

un conjunto de reglas (primarias o fundamentales) que establece quién está autorizado para tomar decisiones colectivas y bajo qué procedimientos... Es necesario también que aquellos que están llamados a decidir o a elegir a quienes deberían decidir, se planteen alternativas reales y estén en condiciones de seleccionar entre una u otra".

Otra característica de la democracia es que el poder de tomar decisiones colectivas (que, al estar autorizado por la ley fundamental se vuelve derecho) se atribuye a un número muy elevado de miembros del grupo. ${ }^{4}$ Por lo que respecta a la modalidad de la decisión la regla fundamental de la democracia es la regla de la mayoría, es decir, la regla con base en la cual se consideran decisiones colectivas y, por lo tanto, obligatorias para todo el grupo. Estas decisiones deben ser aprobadas al menos por la mayoría de las personas que deben tomar la decisión.

Para que un régimen sea democrático, es necesario que los que están llamados a decidir o a elegir a quienes deben decidir, se planteen alternativas reales y estén en condiciones de seleccionar entre una y otra. Para ello es indispensable que a quienes deciden les sean garantizados los llamados derechos de libertad de expresión, de reunión, de asociación, etc. 5

Por liberalismo entenderé la doctrina que ve al Estado como una institución necesaria, para asegurar el orden y la ley en un país y para defender ciertas propiedades individuales. Podemos decir que el liberalismo afirma la importancia de los tres principios fundamentales que Locke definió como: vida, libertad y propiedad". ${ }^{6}$

Dadas estas definiciones de la democracia y del liberalismo podemos notar que su relación ha cambiado a lo largo de la historia. Macpherson, ${ }^{7}$ por ejemplo, señala que los liberales de los siglos

3 Ibid, p. 13.

${ }^{4}$ Ibid, p. 14.

5 Jbid.

${ }^{6}$ The Encyclopedia of Philosophy, Mac Millan company and The Free Press, New York, 1967, Vol.4, P. 458.

${ }^{7}$ C.B. Machperson, La democracia liberal y su época, Madrid, Alianza Editorial, 1981. 
XVII y XVIII, desde Locke a Burke, no eran en absoluto democratas, y al defender con tanto ahinco la propiedad como condición de participación en la vida política, restringieron el voto a una clase minoritaria.

Por otro lado, ciertos demócratas, como Rousseau no eran liberales, ya que los valores del liberalismo, incluso el de la vida, podrían ser anulados si con ello se conservaba el cuerpo social. ${ }^{8}$

Podríamos pensar que actualmente, con la aparición del sufragio universal, de algunas medidas constitucionales de decisión colectiva -como el referendum-, de la regla de cambio en los sistemas legales, la falta de adecuación entre el liberalismo y la democracia ha desaparecido. Sin embargo, esto no es así; existen actualmente teorías liberales que no cumplen con los requisitos de la democracia vistos anteriormente. Por esta razón es necesario analizar ciertos modelos liberales contemporáneos para ver cuáles se acercan más al ideal democrático.

Debo a Macpherson dos ideas fundamentales: primero, la de tratar las teorías políticas como modelos; segundo, la idea de que para que el liberalismo y la demcoracia puedan coexistir es necesaria una concepción de comunidad más fuerte que la que tenemos actualmente y una reducción de la desigualdad política y económica. ${ }^{9}$

Dado que el liberalismo ha afirmado que los derechos a la vida, a la libertad y a la propiedad son individuales, comenzaré analizando dos modelos individualistas: el radical y el igualitario. Terminaré con un modelo comunitarista liberal. La diferencia entre el comunitarismo liberal y ciertas formas de comunitarismo socialista radica en que el primero no pretende, como se verá más adelante, cambiar los principios y las instituciones liberales, mientras que el segundo afirmaría que el liberalismo debería ser abolido por presentar ciertas contradicciones que le son inherentes. 


\section{El individualismo ${ }^{10}$}

Históricamente el término individualismo ha sido utilizado para caracterizar tanto las doctrinas del contrato social que surgen en el siglo XVII como a sus sucesoras que, aun cuando no emplean la noción de contrato, heredan la visión de la sociedad como constituida por individuos, por sujetos que tienen metas, proyectos y fines específicamente individuales.

Las teorías contractualistas consideran que los sujetos se someten al pacto social, porque éste les garantiza el cumplimiento y la realización de esos fines, metas y proyectos. Por su parte, las teorías no contractualistas, como el utilitarismo, afirman que para que la sociedad funcione hay que hacer coincidir esàs metas con las de la mayoría, para que éstas puedan ser satisfechas.

El individualismo es un legado de Hobbes y de Locke; para ellos la sociedad es simplemente un instrumento que nos ayuda a proteger ciertos derechos y a producir algunos bienes en mayor cantidad. Sin embargo, este legado se ha ido puliendo poco a poco de tal manera que ha sido necesario aclarar lo que se dice cuando hablamos de individualismo. Steven Lukes ${ }^{11}$ distingue varias clases de individualismo como son: el ético, el político, el económico y el metodológico.

$\mathrm{El}$ individualismo ético sostiene que la moral es un asunto esencialmente individual. La fuente de la moralidad, es decir, de los valores morales, de los principios éticos y el creador de los criterios de evaluación moral es el individuo. La persona es el árbitro de los valores morales porque goza de autonomía y dignidad. Esta idea es una consecuencia de la teoría moral kantiana, ya que sólo las personas individuales pueden juzgar la universabilidad de sus acciones.

El individualismo político, por su parte, afirma que la sociedad es un conjunto de individuos racionales, generadores de deseos y preferencias y únicos jueces y defensores de sus intereses. Las ideas principales del individualismo político son las siguientes: 1) la legitimidad y la autoridad del gobierno derivan el consentimiento indi-

${ }^{10} \mathrm{Cfr}$. Charles Taylor, Phylosophy and the Human Sciences, Philosophical Papers 2, Cambridge University Press, 1985, p. 25.

${ }^{11}$ Steven Lukes, Individualism, Blackwell, Oxford 1973, pp. 99-122. 
vidual de los ciudadanos; 2) la representación política no es una representación de sectores o de clases, sino de intereses individuales; 3) el propósito del gobierno es proporcionar la satisfacción de las necesidades particulares y la protección de los derechos individuales.

El individualismo económico se basa en la creencia de que las leyes del mercado tienen la racionalidad suficiente para funcionar sin la intervención o con una mínima intervención del Estado. Dicho individualismo supone la propiedad privada de los medios de producción y la libertad en el mercado, tanto para adquirir mercancías como para adquirir fuentes de trabajo.

Por último, el individualismo metodológico afirma que todos los intentos por explicar los fenómenos sociales deben ser rechazados a menos por que sean explicados en términos de hechos sobre individuos.

El individualismo metodológico supone las siguientes creencias: 1) la creencia de que la sociedad, las instituciones y los grupos están formados por individuos que desempeñan ciertos roles, que las tradiciones, las costumbres, las ideologías y el lenguaje son formas en que las personas actúan, piensan y hablan; 2) la creencia en que cualquier proposición sobre los seres humanos o es una proposición que puede ser reducida a individuos o es una proposición sin sentido. Los predicados que se refieren a fenómenos sociales deben ser definidos en términos de predicados que se refieren a fenómenos individuales; 3) la creencia ontológica de que en la sociedad sólo los individuos son reales, los fenómenos sociales son construcciones mentales; 4) la creencia en que las instituciones sociales deben ser explicadas por los fines individuales de las personas que se encuentran en ellas.

Aunque a veces es difícil hacer una separación entre las diversas clases de individualismo cuando examinamos un modelo teórico, es necesario aclarar que el individualismo que analizaré es fundamentalmente el ético y el político. La diferencia entre este modelo y el comunista puede ser explicado por la noción aristotélica de autarkeia, es decir, de autorrealización. Mientras que el individuo afirma que el hombre encuentra su autorrealización y por lo tanto, el bien independientemente de la sociedad y de sus instituciones, el comu- 
nitarismo afirma que los hombres no pueden autorrealizarse sin tomar en cuenta la sociedad, los hombres sólo encuentran su bien en y por las instituciones que ellos mismos han formado. ${ }^{12}$

Como hay una noción común al individualismo ético y al político, que es la de derecho, comenzaré explicando cómo toma este modelo dicha noción.

El modelo individualista supone tres tesis acerca de los derechos:

1. Adscribirle a una persona $A$ un derecho natural (no sólo legal) de $\mathrm{X}$, es afirmar que $\mathrm{A}$ debe ser respetado; esto significa que estamos moralmente comprometidos a no interferir si $\mathrm{A}$ hace o goza de X; la tesis también afirma que la condición de la intervención es forzosa.

2. La condición es forzosa debido a ciertas características o propiedades de A; estas características o propiedades son las capacidades humanas que no sólo definen a las personas protadoras de los derechos, sino también a los derechos que se tienen.

3. Si la condición de la no interferencia es forzosa por las característica o propiedades esenciales del ser humano, es porque éstas tienen un gran valor moral; por ello, no deben sólo no ser interferidas, sino también deben ser desarrolladas.

Estas tesis se aplican a las relaciones entre los individuos así como a las relaciones entre los individuos y el Estado, de ahí su carácter ético y político.

Otra noción de gran importancia para el modelo individualista es el concepto de libertad. La libertad valorada por los protagonistas de la primacía de los derechos, es una libertad por la cual se asume que los hombres son capaces de concebir diferentes alternativas de vida, de llegar a definir lo que realmente quieren y de discernir ciertas reglas que están dispuestos a aceptar. Se asume también, 
que los hombres son capaces de tener creencias racionales y deseos autónomos o que por lo menos tienen medios para distinguir entre éstos y los que no lo son. ${ }^{13}$

Estas asunciones definen lo que es la autonomía que tiene el hombre para trazar sus propios planes y para tomar decisiones en los asuntos básicos y fundamentales de la vida.

La base democrática del modelo individualista estará planteada en la idea de que estos derechos pertenecen por igual a todos los hombres.

Sin embargo, algunos teóricos del individualismo han detectado ciertos problemas en la adscripción igualitaria de los derechos, ya que no basta asignar la igualdad de derechos a todos los hombres para garantizar el ideal democrático. La desigualdad puede surgir no por la asignación de los derechos, sino por su ejercicio. Por ello es necesario hacer una distinción entre el modelo individualista radical, que afirma que basta la noción de derechos, del igualitario, que postula la necesidad de recurrir a un principio igualitario.

\subsection{El individualismo radical}

Llamo individualismo radical al modelo que sostiene tres tesis individualistas: 1)ética; 2) política; y 3) económica.

Este modelo parte de la noción de derecho como restricción moral que marca el límite de lo que puede hacerse o no hacerse a una persona.

Las restricciones morales encuentran su fundamento en la segunda formulación del imperativo categórico, según la cual los individuos son fines y no solamente medios, y como tales, "no pueden ser sacrificados o usados para logar otros fines sin su consentimiento". 14

Los derechos que funcionan como restricciones morales están basados en la creencia de que los individuos poseen racionalidad, libre albedrío, conciencia moral y capacidad para formar y llevar a cabo ciertos planes, es decir, que ellos son capaces de darle un sentido a su vida.

${ }^{13}$ Cfr. Jon Elster, Sour Grapes, Cambridge University Press, Cap. I, 1985. Elster en este libro explica lo que es una creencia racional y un deseo autónomo.

${ }^{14}$ Robert Nozick, Anarchy, State and Utopia, Oxford, Blackwell, 1980, p. 33. 
De esta concepción de los derechos individuales se infiere que el único Estado que los respeta es el Estado mínimo, es decir, el que únicamente redistribuye protección. De la misma manera el único sistema económico justo es el mercado, pues es el único que respeta el derecho que tienen las personas de intercambiar bienes y servicios como más les convenga. El mercado también permite a los individuos la posibilidad de emplearse o no emplearse en el mercado de trabajo.

Los individuos se encuentran en una sociedad con intereses y deseos particulares, la cooperación social se da porque les permite satisfacer mejor esos intereses y deseos. También entran con distintas capacidades y habilidades, por eso el único principio de distribución al que se debe acudir es el de la contribución.

El principio de la contribución afirma que las personas más talentosas deben recibir más que las menos talentosas. Por ejemplo, los profesionistas que tienen más preparación y que por eso ayudan más a la sociedad deben ser mejor remunerados.

Por otra parte, el criterio con el que se evalúa la remuenración que es justa para un individuo es el de la producción marginal, es decir, cada individuo merece lo que es capaz de producir. ${ }^{15}$

Este criterio de distribución es más justo que la remuneración por un salario o por ciertas necesidades.

Este modelo es definido por R. Nozick, quien de un individualismo radical infiere lógicamente que es injusto ponerle trabas a la libre empresa; que un sistema de impuestos viola los derechos de las personas, que cualquier modelo de distribución que no sea "a cada quien lo que escoja y de cada quien como es escogido" interfiere con la libertad, y que hay más argumentos en favor de la desigualdad que en favor de la igualdad.

Me parece que el modelo individualista radical es profundamente antidemocrático. Se ha argumentado ${ }^{16}$ que si viviéramos en una sociedad donde las diferencias fueran sólo de deseos y de intereses, el mercado, sin duda, sería el sistema distributivo más igualitario. Sin embargo, no sólo las diferencias de talentos o capacidades

\footnotetext{
${ }^{15} \mathrm{Ibid}$, p. 160. Este punto se encuentra desarrollado en el célebre ejemplo de Wilt Chamberlain.

${ }^{16}$ Cfr. Ronald Dworkin, Liberalism, Stuart Hampshire (ed.), Public and Private Morality, Cambridge University Press, 1980.
} 
arrojan resultados desiguales, también hay desigualdades de antecedentes. Por ejemplo, los hijos de aquéllos que no tuvieron éxito en el mercado de trabajo empezarán con una desventaja frente a los hijos de los que sí lo tuvieron. Esta desigualdad es perjudicial para la democracia, razón por la cual Machperson afirma

quienes por su educación y ocupación experimentan muchas más dificultades que otros para adquirir, dominar y sopesar la información necesaria para lograr una participación efectiva, se hallan en clara desventaja, una hora de su tiempo consagrada a la participación política no tendrá tanto efecto como una hora de los otros. Así la desigualdad económica crea la apatía política. ${ }^{17}$

La desigualdad económica, pues, viola uno de los requisitos fundamentales del método democrático al eliminar alternativas reales a un gran número de personas.

\subsection{El individualismo igualitario}

Como el modelo individualista radical se aparta del ideal democrático, algunos pensadores que afirman el valor de los derechos individuales han planteado la necesidad de añadirle al modelo un principio de igualdad.

El reto que tienen frente de sí el modelo igualitario, es el de explicar porqué los individuos con deseos, intereses, habilidades y capacidades distintas, están dispuestos a aceptar una distribución que los limite en favor de la igualdad.

El modelo igualitario conserva los elementos característicos del individualismo ético pero modifica el político y desde luego el económico.

La teoría individualista igualitaria actual más representativa es la de John Rawls. ${ }^{18}$

${ }_{18}^{17}$ Macpherson, op. cit. p. 107.

${ }^{18}$ Cfr. John Rawls, Teorta de la Justicia, F.C.E., México, 1981. 
Rawls caracteriza a los individuos como personas libres e iguales. Son libres porque tienen ciertas capacidades racionales y morales que les permiten emitir juicios que son producto del ejercicio de esas capacidades. Las personas son iguales porque cumplen con el requisito de ser miembros cooperativos de la sociedad. ${ }^{19}$

Además de la libertad y la igualdad, las personas tienen dos poderes morales: tienen un sentido de la justicia y un sentido del bien. Por sentido de la justicia entiende Rawls la capacidad de los hombres de entender, de aplicar y de actuar a partir de una concepción de la justicia, por la que se especifican los términos de la cooperación social. Por sentido del bien entiende la capacidad de los hombres de formar, revisar y tratar de alcanzar, racionalmente, ciertos planes necesarios para la realización de su concepción del bien.

De las capacidades mencionadas Rawls deduce tres características de los ciudadanos:

1. Los ciudadanos pueden verse a sí mismos como seres dotados de un poder moral que los capacita para tener una concepción del bien. También son capaces de revisar y cambiar, si es necesario, su concepción de acuerdo con fundamentos racionales y razonables. Los ciudadanos en cuanto personas libres son independientes y no pueden ser identificados con una concepción del bien preestablecida.

2. Los ciudadanos se ven a sí mismos como personas libres, porque son fuentes de las que surgen peticiones válidas. Dichas peticiones tienen un peso que es independiente de los deberes y obligaciones especificadas en la concepción política de la justicia.

3. Los ciudadanos tienen la capacidad de responsabilizarse de los fines que persiguen, así como de la valorización que den a sus peticiones; así, la concepción de la persona como libre, igual, protadora de poderes morales y fuente de peti-

${ }^{19}$ John Rawls, "Justicie as Fairness: Political not Metaphysical", Philosophy and Public Affairs, No. XIV, 1985, pp. 224-251. 
ciones válidas, es la idea básica intuitiva que se encuentra implícita en la cultura pública de una sociedad democrática. $^{20}$

A pesar del acento que pone Rawls en el individualismo ético, ve la necesidad de añadir a su teoría un principio igualitario. Es importante señalar que el principio igualitario -o de la diferenciale permite alejarse del individualistmo radical político y económi$\mathrm{co}^{21}$ ya que el Estado puede intervenir para mitigar la desigualdad, favoreciendo a los más desventajados.

Las personas van a aceptar el principio de la diferencia porque no saben qué lugar van a ocupar dentro de la sociedad, y el hecho de que decidan imparcialmente garantiza la coopeación, puesto que a nadie le gustaría pertenecer a una sociedad en donde sólo él cooperara.

A diferencia del individualismo radical, el igualitario ve ventajas en la cooperación, por lo que es definido de la siguiente manera:

1. La cooperación es distinta de la actividad social coordinada por un grupo o una autoridad central; para que la cooperación exista es necesario que haya un conjunto de reglas, públicamente reconocidas y un conjunto de procedimientos aceptados por los miembros de la cooperación.

2. La idea de cooperación implica la idea de condiciones imparciales de cooperación; esto significa que cada uno de los participantes también las acepten; las personas comprometidas en la cooperación van a resultar beneficiadas por la cooperación de los demás, siempre y cuando cumplan con las tareas asignadas.

3. La idea de cooepración social está relacionada con la idea de que, cooperando, los participantes se acercan a la realización de su concepción del bien; la cooperación especifica una relación de ventaja. ${ }^{22}$

\footnotetext{
${ }^{20}$ Ibid, p. 244.

${ }_{21}^{21}$ Cfr. Rawis, Teoria de la Justicia, op. cit. 302.

22 John Rawls, Justice as Fainerss, op. cit., p. 232.
} 
Paulette Dieterlen

Es conveniente hacer notar que la cooperación, en última instancia, está pensada en favor del bien individual de cada uno de los participantes; razón por la cual, como veremos más tarde, es criticada por el comunitarismo.

Indiscutiblemente, el individualismo igualitario se acerca más al ideal democrático; sin embargo, presenta el siguiente dilema: por una parte, los menos aventajados pueden verse poco favorecidos en relación a los que más ventajas tienen, ya que el principio de la diferencia afirma que las desigualdades son permitidas siempre y cuando la situación de que están peor mejore. Por ejemplo, podríamos pasar de una distribución en la que un individuo tiene una unidad de un bien y otro diez, a una situación en la que el primero tenga dos y el segundo veinte. Dicha distribución sería justa.

Por otra parte, los más favorecidos pueden considerar la obligación que tienen de beneficiar a los que están peor como violatoria de ciertos derechos individuales. Podrían considerar que el modelo individualista igualitario viola los derechos liberales.

Dadas las razones mencionadas anteriormente, ciertos autores 23 piensan que el problema radica en el punto de partida individualista, por esta razón Macpherson afirma que es necesario planteranos una concepción frente de la comunidad para acercarnos al ideal democrático.

Podríamos considerar tres críticas fundamentales del modelo individualista, tanto radical como igualitario: 1) una crítica dirigida al concepto de persona; 2) otra dirigida al concepto de cooperación; 3) una crítica a los principios de justicia distributiva.

La crítica dirigida al concepto de persona que sostiene el individualismo en general, va en dos sentidos: 1) se trata de un concepto de persona ahistórico, trascendental, anterior a cualquier experiencia particular y que es capaz de conocer sus deseos y creencias independientemente del contexto social en el que actua; ${ }^{24}$ 2) hay una confusión entre la capacidad de los agentes para elegir y la capacidad para reflexionar.

${ }^{23}$ Cfr. Taylor, op. cit, Michael Sandel, Liberalism and the Limits of Justice, Cambridge University Press, 1983; Michael Walzer. Spheres of Justice, Martin Robertson, Oxford, 1983.

${ }^{24}$ Cfr. Richard Rorty "La Primacía de la Democracia frente a la Filosofía", Sociologia, UNAM, ano 2, No. 3, 196-1987, pp. 105-128. 
La capacidad para elegir y para reflexionar tienen que distinguirse, ya que por la primera el agente sólo considera planes alternativos en función de sus deseos y creencias; por la segunda, el agente es capaz de examinar sus propias capacidades. Gracias a la reflexión el agente puede conocer sus compromisos con los otros y puede conocer los límites de sus compromisos. ${ }^{25}$

La crítica al concepto de cooperación que sostiene el modelo individualista afirma que éste es incapaz de explicar cualquier acción comunitaria. Los proyectos de explicar una comunidad en términos individualistas sólo llegan a plantearla en términos instrumentales o sentimentales.

La comunidad instrumental es sostenida por el modelo individualista radical. La comunidad se considera como una sociedad privada en la que los individuos consideran los arreglos sociales como cargas necesarias y consideran la cooperación como necesaria para la consecución de ciertos fines individuales.

La comunidad sentimental es sostenida por el modelo individualista igualitario, y en él la comunidad se considera como buena en sí misma. Los miembros de la comunidad comparten ciertos fines. Sin embargo, esta idea de la comunidad es sentimental porque está basada en motivaciones que pueden ser benevolentes y altruistas que pueden desaparecer si chocan con los intereses o con la idea del bien de una persona. Algunos críticos del individualismo ${ }^{26}$ piensan que al traducir comunidad como asociación, compromiso como relación, compartición como reciprocidad y participación como cooperación, perdemos el sentido constitutivo del comunitarismo.

La crítica al principio de justicia distributiva, como se verá más adelante, va dirigida, por una parte al intento de aplicar un solo principio de distribución a sociedades muy complejas, y por otra, al hecho de que el modelo individualista tiene que partir de una situación hipotética que ignora por completo los cambios en la historia y la composición social de una comunidad. Los agentes en el modelo individualista aceptan como justos los modelos de distribución en la situación hipotética, que es ajena a cualquier situación social.

${ }_{26}^{25}$ Michael Sandel, op. cit, p. 154.

${ }^{26}$ Me refiero a Taylor, Sandel y Walzer. 


\section{El comunitarismo}

Debido a los problemas del individualismo, algunos autores como Taylor, Sandel y Walzer ${ }^{27}$ han planteado la necesidad de considerar los temas clásicos del liberalismo desde una perspectiva comunitaria.

El modelo comunitarista es liberal por tres razones: primero, porque considera válidos ciertos conceptos típicamente liberales, como libertad, igualdad, derechos, justicia distributiva, etc; segundo, porque no ve las instituciones liberales como algo que debe ser abolido o modificado en su totalidad, sino más bien las considera como algo que ha sido logrado a través de la práctica política de cietos grupos sociales; tercero, porque distingue entre la justicia en general y la justicia distributiva: mientras que un comunitarismo socialista trataría de cambiar, por ejemplo, una cierta estructura económica y social como el capitalismo, el comunitarismo liberal afirma que se tienen que conservar ciertas estructuras mejorándolas mediante un sistema de justicia distributiva.

Sin embargo, aunque el modelo comunitarista afirma ciertos valores liberales, explica de una manera diferente, así, abandona el individualismo ético, político y económico para dar cuenta nueva del sujeto social, de la cooperación y de la justicia distributiva.

Charles Taylor recurre a la idea aristotélica del hombre como animal social y político que no puede autorrealizarse fuera de la comunidad.

Según esta idea, el hombre sólo puede constituirse como sujeto moral dentro de una comunidad en donde existe un lenguaje y en donde haya un discurso moral. Todos los conceptos morales y políticos que usamos como el de persona, de dignidad, de autonomía, son logros históricos y culturales que necesitaron, para ser aceptados, de la existencia de ciertas instituciones y asociaciones estables y continuas. Estos conceptos no pueden ser considerados como elementos a priori que el hombre posee en una situación hipoiética, previa al surgimiento de la política, sino que dichos conceptos son el resultado de movimientos políticos y sociales, que han quedado plasmados en las instituciones.

${ }^{27}$ Op. cit. 
Un ejemplo de esta tesis lo constituye la interpretación comunitarista del concepto de libertad. Dicho concepto se basa en los siguientes supuestos: primero, el desarrollo de la libertad requiere de una comprensión del sujeto y unicamente mediante esta comprensión las aspiraciones del hombre de lograr cierta autonomía y autodirección se vuelven concebibles; segundo, la comprensión no es algo que podamos conquistar por nosotros mismos, sino que en gran parte es algo que se define a lo largo de nuestras conversaciones con otros y de nuestras prácticas en la sociedad.

Por estas razones la idea del hombre libre requiere de una matriz social. Por esta matriz social, y a través de una serie de prácticas, la sociedad les reconoce a los hombres el derecho que tienen de tomar decisiones y de participar en el debate político.

Otra característica del comunitarismo es la del sujeto dotado de una capacidad de elegir, pero también dotado de una capacidad de reflexionar.

La capacidad de elegir está restringida a varios planes alternativos y a las consecuencias probables que se obtendrían si se eligen esos planes, así como a la intensidad relativa de los deseos e intereses del agente.

Por su parte, la capacidad de reflexioanr nos permite tener una comprensión de nuestra subjetividad que, si bien nunca es transparente, por lo menos no es tan opaca. La reflexión muestra que la subjetividad no es una idea fija, sino que se va conformando a través de la vida y por la participación en la comunidad. También la capacidad de reflexión permite que los agentes posean una autocomprensión en un sentido fuerte, permitiendo a los agentes participar en la constitución de su identidad. ${ }^{28}$ Mientras que para el agente que elige, lo que importa es la deseabilidad de los consumos distintos, que son definidos por los deseos de facto; el que reflexiona también examina los distintos modos de ser un agente. ${ }^{29}$

La manera de concebir a la gente, característica del modelo comunitario, implica una manera peculiar de concebir a la comunidad. La comunidad vista por el modelo no es un instrumento ni un

\footnotetext{
${ }^{28}$ Sandel, op. cit, p. 160.

${ }^{29}$ Sandel, op. cit, p. 154.
} 
sentimiento sino una manera de autocomprensión. Esto equivale a decir que los miembros de la sociedad conciben su identidad por el grupo del que forman parte.

Para los defensores del comunitarismo, el problema del individualismo es que al distanciar los sujetos los sumerge en una circunstancia ajena a ellos. El sujeto del individualismo se encuentra fuera de la política y por ello queda convertido en artículo de fe. En palabras de Sandel, ${ }^{30}$ el individualismo minimiza el peligro de que cuando la política marcha mal surge el desencanto, y olvida la posibilidad de que cuando la política va bien nos demos cuenta de que podemos conocer en común lo que no podemos conocer solos.

El último punto que diferencia al comunitarismo del individualismo es el que se refiere a la manera de concebir la justicia distributiva. $^{31}$

Los modelos que parten de la noción del hombre como animal social no parten, como lo hace el individualismo, de una situación hipotética -estado de naturaleza, posición original, etc-- sino que afirman la existencia de una estructura social que es la condición del desarrollo de las potencialidades del hombre. Esta estructura puede ser la familia, la polis, la sociedad sin clases, etc.

Esto equivale a decir que existe una situación social antecedente, necesaria para plantear cualquier modelo de justicia distributiva. También significa que el tejido de la distribución está determinado por el carácter de los bienes que van a ser distribuidos, ya que éstos han variado históricamente.

Ahora bien, la estructura no puede ser cuestionada en nombre de la justicia distributiva; por ejemplo, si nos encontramos ante una sociedad de castas, tenemos que tomar en cuenta que se les dará más a aquéllos que ocupan un lugar privilegiado. Tampoco se podría objetar, en nombre de la igualdad, el status especial o el privilegio de un rey o un sacerdote en una concepción jerárquica de la sociedad. Estos aspectos son importantes para plantear el problema de la distribución, ya que si en una sociedad la estructura más importante es la familia, por ejemplo, no tiene porqué hacerse la

${ }^{30} \mathrm{Ibid}$, p. 22.

${ }^{31}$ Cfr. Taylor, op. cit, pp. 289-317. 
distribución de acuerdo con los individuos. También es importante tomar en cuenta los bienes particulares para distribuir ya que éstos pueden variar.

El conocimiento de la estructura también permite conocer las potencialidades humanas y saber cómo pueden realizarse esas potencialidades.

Una vez que se tiene detectada la estructura, se deben considerar los principios de la justicia distributiva. Tomando en cuenta que la idea del hombre como animal social está relacionada con la idea de un bien común, parece claro que ciertas personas merecen más que otras porque su contribución al bien común es más importante.

Esta idea está basada en un principio de contribución que Taylor llama: mitigado.

El principio de contribución mitigado tiene dos características: primera, la afirmación de que dado que la vida en común ayuda a los hombres a realizar sus potencialidades, aquellas personas que contribuyen más a la comunidad merecen más; segunda, la afirmación de que dado que la vida comunitaria es un bien en sí mismo, al adquirir ese bien estamos obligados a pagar una deuda, y ésta nos lleva a respetar los principios de la distribución.

Tanto las cuestiones de la estructura como las del principio de la contribución mitigada se derivan de la naturaleza de la asociación y de los bienes perseguidos en común. Esto significa que las demandas de la justicia distributiva pueden ser diferentes en distintos momentos de la historia y en sociedades diferentes.

El error de las teorías individualistas, incluyendo las igualitarias, consiste en operar como si existiera un criterio único de la distribución. Por su parte el comunitarismo afirma que puede haber varios criterios de distribución. En algunas circunstancias un criterio de distribución que responda a las necesidades puede tener prioridad sobre el criterio de la contribución.

Ahora bien, las sociedades occidentales se caracterizan por descansar en estructuras igualitarias. Por ejemplo, ya no pensamos que ciertos individuos porque nacieron en una determinada familia merecen más que otros, o que algunos individuos por ser de algún color merecen más. 
Por esta razón, la idea que subyace a los problemas de la justicia distributiva es la idea de igualdad. Las ideas básicas respecto a la igualdad se expresan en una preocupación por nivelar las diferencias permitidas en salarios e ingresos y en una preocupación por implementar políticas igualitarias. Estas dos ideas igualitarias son las condiciones de posibilidad de la democracia, ya que su cumplimiento permite que un mayor número de personas tengan oportunidad de participar o de ser representadas en los debates políticos.

Creo que es evidente que el modelo que más se adapta al ideal democrático tal y como lo plantean Bobbio y Macpherson es el comunitarismo, por varias razones.

Primero, porque la democracia puede verse como un bien social en sí y no simplemente como un instrumento político que permite a los individuos satisfacer sus intereses particulares.

Segundo, por el énfasis que pone en la existencia de ciertas estructuras sociales previas a cualquier distribución, este aspecto nos obliga a considerar la importancia de los estudios empíricos sobre los grupos sociales. Dichos estudios nos pueden dar un conocimiento de las necesidades de la sociedad, señalando cuáles son los recursos que se deben distribuir y mostrando las posibilidades reales, aquéllas que van hacia la descentralización y la autoadministración.

Tercero, el modelo comunitario, al plantear la necesidad de tomar en cuenta la existencia de una diversidad de grupos dentro de una sociedad coincide con la visión de la democracia como una estructura piramidal. Macpherson piensa que puede existir una democracia directa a través de pequeños grupos, como habitantes de un barrio, obreros de una fábrica, asociaciones feministas, etc. En estos grupos se llevarían a cabo debates directos, se tomarían decisiones por consenso o por mayoría y se eligirían delegados que formarían un consejo en un nivel más amplio, como por ejemplo, un distrito o una pequeña ciudad. Los delegados contarían con instrucciones de sus electores y serían responsables ante ellos. Así se llegaría a un nivel más alto, como por ejemplo un consejo nacional. ${ }^{32}$

${ }^{32}$ Machperson, op. cit., p. 130. 
Cuarto, el comunitarismo permite tener una visión de la democracia como una conquista histórica y como un bien común que debemos conservar y perfeccionar para dar la oportunidad real, como lo afirma Bobbio, a que más personas participen en la vida política en un país.

Sin duda, con frecuencia creemos que este modelo es ilusorio o utópico, porque creemos que el comunitarismo es algo ajeno a nuestra realidad social. Sin embargo, nos queda la posibilidad de pensar acerca del comunitarismo, lo que Aristóteles pensó de la amistad, que no se asemeja a una emoción, sino a una virtud y como tal, requiere del hábito. ${ }^{33}$

${ }^{33}$ Aristóteles, Etica nicomaquea, Instituto de Investigaciones Filológicas, UNAM, 1983, p. 190. 